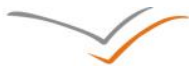

\title{
VERSITA
}

\section{Habit Formation and Preference Change with Capital and Renewable Resources}

\author{
Wei-Bin Zhang
}

Ritsumeikan Asia Pacific University, College of International Management, Japan

\begin{abstract}
Background: Although there are many formal models about interactions among habit formation, preference change and the economic growth, only a few formal models examine implications of habit formation and preference change for the economic growth with resources. Objectives: This paper builds an economic growth model with endogenous physical capital, renewable resources, habit formation and preference. Methods: Although it is influenced by the Ramsey growth theory with time preference and habit formation, the paper applies a new approach to the household behaviour. Results: We plot the motion of the economy and conduct a comparative dynamic analysis with regard to certain parameters to obtain insights into interactions between the preference and the economic structural changes. Conclusions: We have shown that habit formation and preference change have significant effects on the economic grow and resources utilization both with regard to the transitional paths and the long-run equilibrium.
\end{abstract}

Keywords: Renewable resources, habit formation, preference change, economic growth and structural change

JEL main category: Economic Development, Technological Change, and Growth

JEL classification: O41, Q21

Paper type: Research article

Received: 3, April, 2013

Revised: 15, May, 2013

Accepted: 26, October, 2013

Citation: Zhang, W-B. (2013), "Habit Formation and Preference Change with Capital and Renewable Resources", Business Systems Research, Vol. 4, No. 2, pp. 108-125.

DOI: 10.2478/bsri-2013-0016

Acknowledgements: The author is grateful to the financial support of the Grants-in-Aid Scientific Research from The Japan Society for the Promotion of Science.

\section{Introduction}

The main purpose of this research is to deal with dynamic interdependence among economic growth, resource change, habit formation and preference shift. Some empirical studies confirm existence of interdependent relations between preference changes and other changes in social and economic conditions (for instance, Fuchs, 1982; Horioka, 1990; Becker et al., 1997; Sheldon, 1998; Kirby et al. 2002; and Chao et al., 2009). One may also find some formal models on the subject in the literature of economic growth (Uzawa, 1968; Epstein, 1987; Shi and Epstein, 1993; Palivos et al. 1997; Drugeon, 1996, 2000; and Dioikitopoulos et al., 2010). The modeling of preference change in this study follows by the growth models of time preference change and habit formation in the Ramsey-type neoclassical growth theory (e.g., Lucas et al., 1984; Stern, 2006; Meng, 2006). Becker et al. (1997, p. 729) observe: "Time preference plays a fundamental role in theories of saving and investment, economic growth, interest rate determination and 
asset pricing, addiction, and many other issues that are getting increasing attention from economists. Yet, ... rates of time preference are almost invariably taken as 'given' or exogenous, with little discussion of what determines their level." As explained late, in order to model behavior of the household with endogenous preference change, this study adopts the main ideas in this approach to an alternative utility approach by Zhang.

Renewable resources are important components of national production and consumption. There are formal models on growth with natural resources in the 1970s (e.g., Plourde, 1970, 1971, Stiglitz, 1974; Clark, 1976; Dasgupta et al., 1979). This study is to examine dynamic interactions among economic growth, habit formation and preference change, renewable resources, basing on the Ramsey-type neoclassical growth theory of endogenous capital and renewable resource by, for instance, Eliasson et al. (2004) and Alvarez-Cuadrado et al. (2011). Renewable resources, such as forest or a fish species, play important role even in some economies. Some empirical studies by Gylfason, et al. (1999), Barbier (1999), Sachs et al. (2001), and Chen et al. (2009) show that natural resources may have either an adverse or positive effect on economic growth. The economic growth mechanism of the model in this study is much influenced by on the neoclassical growth theory. Solow (1999) discusses how to take account of dynamic interdependence between natural resources and growth within the neoclassical growth theory. According to Solow, it is not difficult to introduce renewable resources into the neoclassical growth theory when the resource good is utilized as an input in the production. Solow did not mention how to incorporate possible consumption of renewable resource into the neoclassical growth theory (see also, Beltratti, et al., 1994, Ayong Le Kama, 2001). Our model contains the renewable resource as a source of utility.

This study deals with interdependence among growth, preference change, habit formation and dynamics of renewable resources. The study applies the approach to consumers' behavior proposed by Zhang (1993).The paper is an integration of the two models by Zhang $(2011,2012)$. Zhang (2011) introduces resource into the neoclassical growth theory with Zhang's utility function, while Zhang (2012) deals with habit formation and preference change in a one-sector neoclassical growth framework without taking account of resource. The reminder of the paper is arranged as follows. First, we build the economic growth model with interactions among wealth accumulation, renewable resource dynamics, habit formation and preference change. Then we study properties of the dynamic model, proving existence of equilibrium and checking stability conditions by simulation. Finally, we conduct comparative dynamics analysis with regard to some parameters. The main results in section 3 are proved in the appendix.

\section{The Basic Model}

The economy produces and consumes one (durable) good and one renewable resource. The economy consists of the industrial sector (which produces goods for consumption and investment) and the resource sector (which produces renewable resources). The commodity is chosen as numeraire. The price of the commodity is set to 1 . The industrial sector is the same as in the standard one-sector neoclassical growth theory. We refer the one-sector model to, for instance, Solow (1956); Burmeister et al. (1970); and Barro et al. (1995) .Households own capital and the markets are perfectly competitive. The homogenous population is fixed. The two input factors are fully employed.

\section{The industrial sector}

We use the conventional production function to describe the relationship between two input factors, the labor force $N_{i}(t)$ and physical capital $K_{i}(t)$, and output $F_{i}(t)$. The industrial sector's production function is

$$
F_{i}(t)=A_{i} K_{i}^{\alpha_{i}}(t) N_{i}^{\beta_{i}}(t), A_{i}, \alpha_{i}, \beta_{i}>0, \alpha_{i}+\beta_{i}=1(1)
$$

where $A_{i}$ is the total productivity, and $\alpha_{i}$ and $\beta_{i}$ are respectively the output elasticises of capital and labour. Let $r(t)$ and $w(t)$ stand for the rate of interest and wage rate respectively. The marginal conditions for the industrial sector are 


$$
r(t)+\delta_{k}=\frac{\alpha_{i} F_{i}(t)}{K_{i}(t)}, w(t)=\frac{\beta_{i} F_{i}(t)}{N_{i}(t)} \cdot(2)
$$

We use $\delta_{k}$ to represent the fixed depreciation rate of physical capital. The depreciation rate is assumed to be independent of the manner of use.

The renewable resources sector

We follow Zhang (2011) in modelling the renewable resources sector. We use $X(t)$ to represent the stock of the renewable resource. We model the natural growth rate of the resource with the logistic function. The growth rate is considered as a function of the existing stock as follows

$\phi_{0} X(t)\left(1-\frac{X(t)}{\phi}\right), \phi_{0}, \phi>0$.

In the above equation "uncongested" or "intrinsic" growth rate of the renewable resource is denoted by $\phi_{0}$. Here, $\phi$ stands for the carrying capacity of the resource. The carrying capacity is the maximum possible size for the resource stock. If the stock is equal to $\phi$, there is no change the stock. If the current stock is much lower than the carrying capacity, the growth rate per unit of the stock is close to the intrinsic growth rate. There are many applications of the logistic model in the literature of dynamic interdependence between economic growth and renewable resource (e.g., Brander et al., 1998; Hannesson, 2000; Cairns et al., 2010). This study assumes the carrying capacity and the intrinsic growth rate to be constant. In the study by Jinji (2006), for instance, the carrying capacity and the intrinsic growth rate are endogenous. The change rate in the stock is equal to the natural growth rate minus the harvest rate

$$
\dot{X}(t)=\phi_{0} X(t)\left(1-\frac{X(t)}{\phi}\right)-F_{x}(t)(3)
$$

where $F_{x}(t)$ is the harvest rate of the resource. Following Gordon (1954), we accept the assumption of the nationally owned open-access renewable resource. The scale of harvesting is determined by the condition that the current return to the representative entrant is equal to the cost of entrant. Let $N_{x}(t)$ and $K_{x}(t)$ stand for respectively the labor and capital inputs of the resource sector, The harvesting production function is taken on the following form

$$
F_{x}(t)=A_{x} X^{b}(t) K_{x}^{\alpha_{x}}(t) N_{x}^{\beta_{x}}(t), A_{x}, b \geq 0, \alpha_{x}, \beta_{x}>0, \alpha_{x}+\beta_{x}=1(4)
$$

where $A_{x}, b, \alpha_{x}$ and $\beta_{x}$ are parameters. This function is more general than some well-used functions for modeling harvesting. For instance, the Schaefer harvesting production function (Schaefer, 1957) is a special case of (4)

$$
F_{x}(t)=A_{x} X(t) N_{x}(t)
$$

We use $p(t)$ to stand for the price of the stock. The marginal conditions of the resource sector are

$$
r(t)+\delta_{k}=\frac{\alpha_{x} p(t) F_{x}(t)}{K_{x}(t)}, w(t)=\frac{\beta_{x} p(t) F_{x}(t)}{N_{x}(t)} .(5)
$$

The conditions that labor and capital are fully employed are

$$
K_{i}(t)+K_{x}(t)=K(t), N_{i}(t)+N_{x}(t)=N(6)
$$


where $N$ and $K(t)$ stand for respectively the (fixed) labor force and total capital stock.

\section{Consumer's behavior}

We use the approach by Zhang (1993) to model preference structure of consumers. Let per capita wealth be denoted by $k(t)$. We have $k(t)=K(t) / N$. The representative household's current income is the sum of the wage payment $w(t)$ and the interest payment $r(t) k(t)$. That is

$$
y(t)=r(t) k(t)+w(t)
$$

We have the disposable income as follows

$$
\hat{y}(t)=y(t)+k(t)=(1+r(t)) k(t)+w(t) \cdot(7)
$$

We use $s(t), c(t)$, and $c_{x}(t)$ to stand for, respectively, saving, consumption of the commodity and consumption of the resource good. The representative household distributes the disposable income among the three variables, $s(t), c(t)$, and $c_{x}(t)$. The representative household is thus faced with the following budget constraint

$$
c(t)+s(t)+p(t) c_{x}(t)=\hat{y}(t) \cdot(8)
$$

The representative household decides $s(t), c(t)$, and $c_{x}(t)$ by maximizing the following utility function

$$
U(t)=c^{\xi_{0}(t)}(t) s^{\lambda_{0}(t)}(t) c_{x}^{\chi_{0}(t)}(t), \quad \xi_{0}(t), \lambda_{0}(t), \chi_{0}(t)>0
$$

where $\xi_{0}(t)$ is the utility elasticity of consumer goods, $\lambda_{0}(t)$ the utility elasticity of saving, and $\chi_{0}(t)$ the utility elasticity of resource good. We call $\xi_{0}(t), \lambda_{0}(t)$, and $\chi_{0}(t)$ respectively the propensities to consume, to own wealth, and to consume the resource good. Different from Zhang (2011) where the propensities are constant parameter, this study treats the propensities as endogenous variables. It should be remarked that equations (1)-(9) are based on Zhang (2011). Maximizing $U(t)$ subject to (8) yields

$c(t)=\xi(t) \hat{y}(t), \quad s(t)=\lambda(t) \hat{y}(t), \quad p(t) c_{x}(t)=\chi(t) \hat{y}(t)(10)$

where

$$
\xi(t) \equiv \rho(t) \xi_{0}(t), \quad \lambda(t) \equiv \rho(t) \lambda_{0}(t), \quad \chi(t) \equiv \rho(t) \chi_{0}(t), \quad \rho(t) \equiv \frac{1}{\xi_{0}(t)+\lambda_{0}(t)+\chi_{0}(t)} .
$$

We call $\xi(t)$ is called the relative propensity to consume, $\lambda(t)$ the relative propensity to own wealth, and $\chi(t)$ the relative propensity to consume the resource good. It can be seen that it is the relative values of the propensities that affect the household's decision. According to the definition of $s(t)$, the household's wealth is accumulated according to

$\dot{k}(t)=s(t)-k(t)$

The equation simply states that the saving minus the dissaving is equal to the change in wealth.

Demand and supply

The demand for the resource equals the supply of the resource 
$c_{x}(t) N=F_{x}(t)$.

The industrial sector's output equals the sum of the total consumption, the depreciation of capital stock and the net saving, i.e.

$C(t)+S(t)-K(t)+\delta_{k} K(t)=F_{i}(t)$

where

$C(t) \equiv c(t) N, \quad S(t) \equiv s(t) N$.

The time preference and the propensity to hold wealth

Influenced by the current literature on time preference change, we now introduce endogenous propensity to save. To illustrate the traditional way of modeling time preference change, we consider the study by Chang et al. (2011). The representative household's discounted lifetime utility is

$\int_{0}^{\infty} u(c, m) e^{-\rho(t)} d t$

where $u$ is the utility function, $c(t)$ is consumption, and $m(t)$ is holdings of real money balances. The household maximizes the utility subject to the budge constraint. Following Uzawa's model of preference change, Chang et al. specify the following change in the cumulated subjective discount rate

$\rho(t)=\int_{0}^{t} \Delta(u(s)) d s$

where $\Delta>0$ is an instantaneous subjective discount rate at time $s$, which satisfies $\Delta^{\prime}>0, \Delta^{\prime \prime}>0$, and $\Delta-u \Delta^{\prime}>0$. Similar formations are also referred to Uzawa (1968), Epstein (1987), Obstfeld (1990), and Shi and Epstein (1993), We have

$\dot{\rho}(t)=\Delta(u(t))$.

There are other models of time preference change in the literature (e.g., Dornbusch et al., 1973; Persson et al., 1985; Blanchard et al., 1989; Das, 2003; Kam et al., 2006, and Hirose et al., 2008) which consider the rate of time preference to be a function of real wealth. The rate of time preference is assumed to rise with real wealth. Influenced by these studies and Zhang (2012), we consider the following dynamics of the propensity to save

$$
\lambda_{0}(t)=\bar{\lambda}+\lambda_{w} w(t)+\lambda_{k} k(t), \quad(14)
$$

where $\bar{\lambda}>0, \lambda_{w}$, and $\lambda_{k}$ are parameters. The signs of $\lambda_{w}$ and $\lambda_{k}$ are not specified because the propensity to save may be positively or negatively related to the wage rate and wealth.

The habit formation and the propensity to consume consumer goods

The idea of habit formation or habit persistence was formally proposed by Duesenberry (1949). According to this approach, consumers tend to get accustomed to a given "standard of living" which they like to keep. Becker (1992) illustrates: "the habit acquired as a child or young adult generally continue to influence behavior even when the environment changes radically." Habit formation is applied to different economic issues (for instance, Mehra et al., 1985; de la Croix, 1996; and Campbell et al., 1999; Ravn et al., 2006; Boldrin et al. 2001; and Huang, 2012). We now introduce dynamic mechanism for the propensity to consume the commodity. Our approach is influenced by the idea of habit formation in the literature of growth and habit 
formation. Corrado et al. (2011) model the behavior of an infinitely lived representative by assuming that the consumer maximizes his expected utility

$$
U=E_{t}\left\{\sum_{j=1}^{\infty} \beta^{j} U_{t+j}(.)\right\}
$$

where $U_{t+j}($.$) is the instantaneous utility function, \beta=1 /(1+\theta)$ is the coefficient of the impatience to consume and $\theta$ is the subjective rate of time preference. The utility function is specified as

$$
U_{t}=\frac{\left(C_{t} \hbar_{t}^{-v}\right)^{1-\alpha}}{1-\alpha}
$$

where $C_{t}$ is consumption at time $t, \hbar_{t}$ is the stock of habit with regard to the consumption good, and $\alpha$ is a coefficient. The parameter $v$ measures the power of the habit stock in influencing the behavior. If $v=0$, habit does not exert influence on the consumer's decision making. If $v=1$, the ratio of the consumption and the stock of habit is important. The above form of the utility function is called multiplicative, in contrast to the subtractive formation $\left(C_{t}-\hbar_{t}\right)$. The implications of multiplicative form are referred to Carroll (2000); Amanto et al. (2004). The implications of the subtractive formation are referred to Deaton et al. (1980). Corresponding to the discrete formation of habit formation, Alvarez-Cuadrado et al. (2004) and Gómez (2008) use a habit formation in continuous time

$$
\hbar(t)=\rho \int_{-\infty}^{t} e^{\hbar_{0}(s-t)} C^{\phi}(s) \bar{C}^{1-\phi}(s) d s, \quad \rho>0, \quad 0 \leq \phi \leq 1
$$

where $C(t)$ is the consumption level of the consumer and $\bar{C}(t)$ is the economy-wide average consumption. If $\hbar_{0}$ is lower, higher weights are put to more distant values of the levels of consumption. This parameter measures the relative weights of consumption at different times. Taking derivatives of the above equation with respect to time, we get

$$
\dot{\hbar}(t)=\hbar_{0}\left[C^{\phi}(s) \bar{C}^{1-\phi}(s)-\hbar(t)\right] .
$$

If $\phi=0$, the habit formation corresponds to the model with external habits. If $\phi=1$, the habit formation corresponds to the model with internal habits. If $0<\phi<1$, habits arise from both the consumer's and average past consumption.

On the basis of the habit formation in the literature of growth with endogenous habits, like Zhang (2012) we propose the habit formation with regard to consumer goods as follows

$$
\dot{\hbar}_{c}(t)=\tilde{\xi}\left[c(t)-\hbar_{c}(t)\right]
$$

This formation is based on the internal habit formation in the literature. If the current consumption is lower than the level of the habit stock, then the level of habit stock tends to fall, and vice versa. Following Zhang (2012), we consider the propensity to consume to be a function of the wage income and the habit stock specified as

$$
\xi_{0}(t)=\bar{\xi}+\xi_{w} w(t)+\xi_{h} \hbar_{c}(t) \quad(16)
$$

where $\bar{\xi}>0, \xi_{w}$ and $\xi_{h}$ are parameters. If $\xi_{w}=\xi_{h}=0$, the propensity is constant. If $\xi_{w}>(<) 0$, a fall in the wage rate reduces (augments) the propensity to consume. It is reasonable to assume $\xi_{w} \geq 0$, at least for normal goods. If the goods under consideration are inferior, the sign may be opposite. In reality, relations between wage and consumption are situation-dependent (e.g., 
Lusardi, 1996; Storesletten, et al. 2004; and Lise and Seitz, 2011). The term $\xi_{h} \hbar_{c}$ implies that the propensity to consume is proportional to the habit stock.

The habit formation and the propensity to consume the resource

We model the change in the propensity to use the resource in a similar way to modeling endogenous propensity to consume the commodity. The evolution of the habit stock for resource consumption $\hbar_{x}(t)$ is

$$
\dot{\hbar}_{x}(t)=\tilde{\chi}\left[c_{x}(t)-\hbar_{x}(t)\right]
$$

where $\tilde{\chi}$ is the relative weights of resource consumption at different times. Corresponding to (16), we model the endogenous propensity to use the resource as

$\chi_{0}(t)=\bar{\chi}+\chi_{w} w(t)+\chi_{x} \hbar_{x}(t)$

where the parameters, $\bar{\chi}$ and $\chi_{x}$ are usually nonnegative, the sign of $\chi_{x}$ is ambiguous. For instance, a rise in wage rate may result in a higher or lower propensity to consume fishes.

The construction of the dynamic model is completed now. We deal with the dynamic properties of the economic system.

\section{The Dynamic Properties and the Motion of the System}

The appendix proves that the motion of the dynamic model with habit formation ad preference change is given by 4 autonomous differential equations with 4 variables, $z(t), X(t), \hbar_{c}(t)$ and $\hbar_{T}(t)$, in which the new variable $z(t)$ is defined as

$z(t) \equiv \frac{\beta_{j} K_{i}(t)}{\alpha_{i} N_{i}(t)}$

From the solution of the time-invariant system, we determine all the other variables in the economy at any point of time. The appendix confirms the following lemma.

Lemma 1

We determine the motion of the economic system with the following 4 autonomous differential equations with $z(t), X(t), \hbar_{c}(t)$ and $\hbar_{T}(t)$ as the variables

$$
\begin{aligned}
& \dot{z}(t)=\Lambda_{z}\left(z(t), X(t), \hbar_{c}(t), \hbar_{x}(t)\right), \\
& \dot{X}(t)=\Lambda_{X}\left(z(t), X(t), \hbar_{c}(t), \hbar_{x}(t)\right), \\
& \dot{\hbar}_{c}(t)=\Lambda_{c}\left(z(t), X(t), \hbar_{c}(t), \hbar_{x}(t)\right), \\
& \dot{\hbar}_{x}(t)=\Lambda_{x}\left(z(t), X(t), \hbar_{c}(t), \hbar_{x}(t)\right)(19)
\end{aligned}
$$

in which $\Lambda_{z}, \Lambda_{X}, \Lambda_{c}$, and $\Lambda_{x}$ are functions of $z(t), X(t), \hbar_{c}(t)$ and $\hbar_{T}(t)$ given in the appendix. We determine all the other variables are as functions of $z(t), X(t), \hbar_{c}(t)$ and $\hbar_{T}(t)$ as follows: $r(t)$ and $w(t)$ by $(\mathrm{A} 2) \rightarrow p(t)$ by $(\mathrm{A} 3) \rightarrow \xi_{0}(t)$ and $\chi_{0}(t)$ by $(\mathrm{A} 11) \rightarrow \lambda_{0}(t)$ by $(\mathrm{A} 10) \rightarrow \lambda(t), \xi(t)$, and $\chi(t)$ by $(10) \rightarrow K_{i}(t)$ and $K_{x}(t)$ by $(\mathrm{A} 6) \rightarrow K(t)=K_{i}(t)+K_{x}(t) \rightarrow k(t)=K(t) / N \rightarrow N_{i}(t)$ and $N_{x}(t)$ by $(\mathrm{A} 1) \rightarrow$ $F_{i}(t)$ by $(1) \rightarrow F_{x}(t)$ by $(4) \rightarrow \hat{y}(t)$ by $(7) \rightarrow c(t), c_{x}(t)$ and $s(t)$ by (10).

From the procedure in Lemma 1, we solve the values of all the variable at any point of time as functions of $z(t), X(t), \hbar_{c}(t)$ and $\hbar_{T}(t)$. As the four dimensional autonomous differential equations is nonlinear, it is almost impossible to find explicitly analytical solutions of the time-invariant system. Nevertheless, a common portable computer can help us to simulate the autonomous 
differential equations with known initial conditions. For illustration, we plot the motion of the economic system. Firs, the parameter values are specified as

$$
\begin{aligned}
& N_{0}=5, A_{i}=1, A_{x}=0.5, \alpha_{i}=0.3, \alpha_{x}=0.4, \bar{\lambda}=0.6, \lambda_{w}=-0.01, \quad \lambda_{k}=0.02, \quad \tilde{\xi}=0.1, \quad \bar{\xi}=0.1, \\
& \xi_{w}=0.01, \quad \xi_{h}=0.02, \tilde{\chi}=0.1, \bar{\chi}=0.06, \chi_{w}=0.01, \chi_{h}=0.02, \phi_{0}=6, \phi=1, \quad b=0.1, \delta_{k}=0.05 .
\end{aligned}
$$

We fix the depreciation rate at $\delta_{k}=0.05$. We choose the population 5 . In our neoclassical model the population size does not affect the per-capita variables, even though it explains the size of the economy by multiplication. The chosen value of the population will not affect our main conclusions. The total productivity and the output elasticity of capital of the industrial sector are respectively 1 and 0.3 , and the total productivity and the output elasticity of capital of the resource sector are respectively 0.5 and 0.4 . Both in theoretical simulations and empirical studies the output elasticity of capital in the Cobb-Douglas production is often valued approximately equal to 0.3 and the value of the total productivity is chosen to be close to unity (e.g., Miles and Scott, 2005; Abel, et al., 2007). Although the selected values of the parameters for the preference are not empirically based, we choose the coefficients associated with the wage and wealth very small. The small disturbances imply that the preference change may not structurally affect the dynamic system. To plot the motion of the system, we specify the following initial conditions

$$
z(0)=6, X(0)=0.7, \hbar_{c}(0)=0.6, \hbar_{x}(0)=1 .
$$

The simulation result is plotted in Figure 1.

Figure 1

The Motion of the Economic System
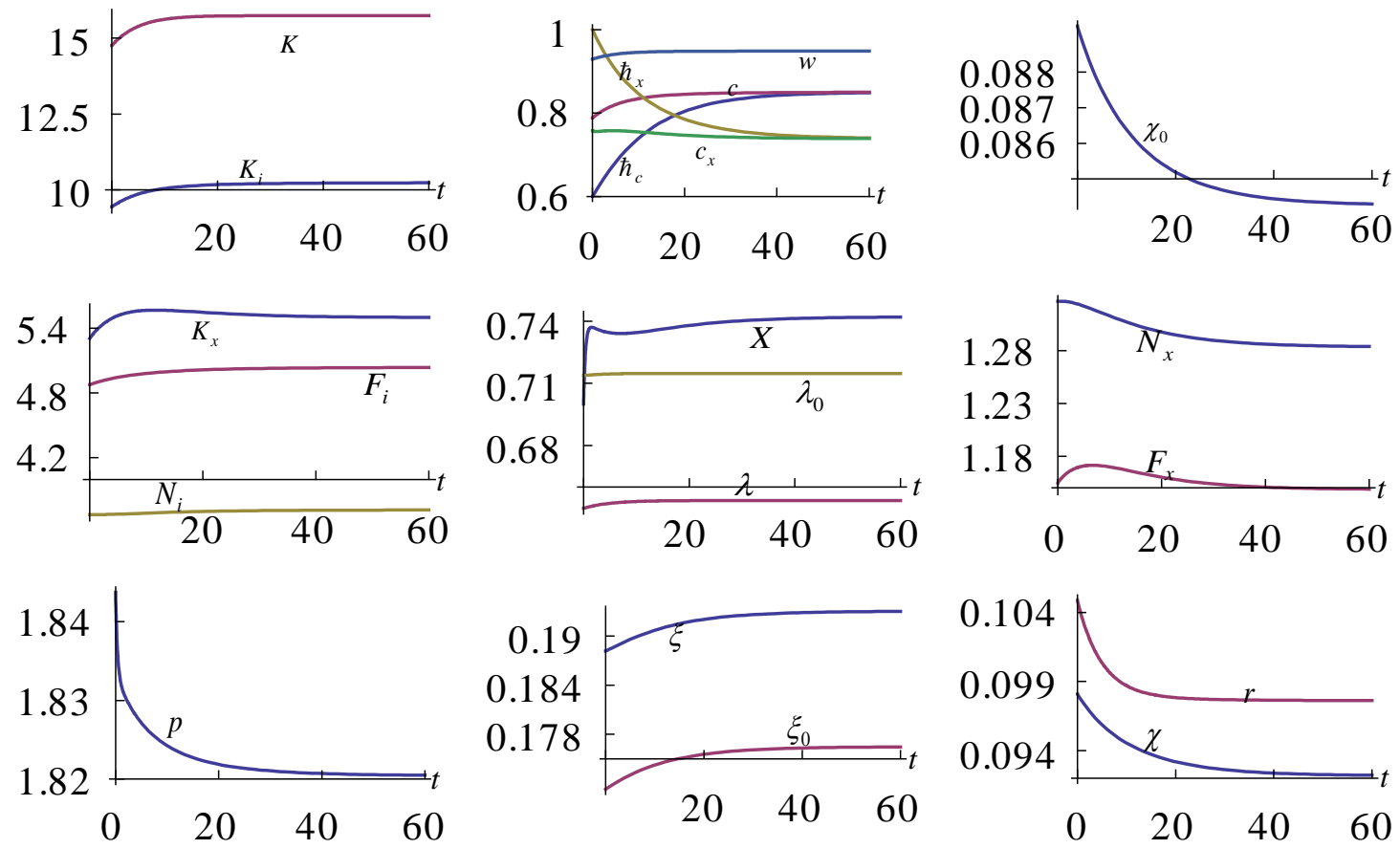

We see that the habit stock of resource consumption falls while the habit stock of commodity consumption rise till they respectively approach the consumption levels of resource and commodity. This occurs because the habit stocks are initially different from their corresponding variables. The labor force is shifted from the resource sector to the industrial sector. The total capital is augmented in association with the increase in the propensity to save. The capital inputs of the two sectors are enhanced in association with the augment in 
the total capital. The harvesting output is augmented initially and subsequently is reduced in association with the fall in the relative propensity to consume the resource. As the total capital is increased, the rate of interest is lowered. The wage rate is enhanced. The falling in the propensity to consume the resource makes the price of the resource to fall. The consumption level and habit stock of commodity consumption are increased in association with the rise in the relative propensity to consume.

Figure 1 demonstrates that all the variables move towards stationary states. This hints the existence of equilibrium. Our simulation identifies the equilibrium values of these variables as follows

$F=7.13, \quad K=15.74, \quad X=0.74, \quad r=0.098, \quad p=1.82, \quad w=0.95, \quad F_{i}=5.04, \quad F_{X}=1.15, \quad N_{i}=3.72$,

$N_{x}=1.28, \quad K_{i}=10.24, \quad K_{x}=5.5, \quad \xi_{0}=0.18, \quad \chi_{0}=0.08, \quad \lambda_{0}=0.65, \quad \xi=0.19, \quad \chi=0.09, \lambda=0.72$,

$c=\hbar_{c}=0.85, c_{x}=\hbar_{x}=0.74$

in which $F$ is the GDP defined by

$$
F(t)=F_{i}(t)+p(t) F_{s}(t)
$$

Its eigenvalues are

$$
\{-2.91,-0.18,-0.12,-0.08\} \text {. }
$$

The equilibrium point is locally stable. Hence, the system always approaches its equilibrium if it is not far from the equilibrium point. This means that we can effectively conduct local comparative statics analysis with regard to transitional processes as well as equilibrium. It is straightforward to identify another equilibrium point

$z=6.36, \quad X=0.26, h_{c}=0.84, h_{x}=0.83$.

At this equilibrium the eigenvalues are

$\{2.85,-0.18,-0.12,-0.09\}$.

This is a saddle pint. Hence, we are focused on the equilibrium point given in (21).

\section{Comparative Dynamic Analysis}

The previous section shows that the economic system has two equilibrium points - one is a saddle point and the other one is a locally stable equilibrium. As we can make effectively comparative dynamic analysis, this section is concerned with the impacts of exogenous changes in some parameters on the path approaching to the stable equilibrium. As the timeinvariant system involves many variables with complicated nonlinear interactions, it is difficult to accurately interpret how all these variables interact over time. We introduce a variable $\Delta x(t)$ which stands for the change rate of the variable $x(t)$ in percentage due to changes in some parameter value.

Lower weights being put to more distant values of consumption level of resource

First we allow lower weights to be given to more distant values of the levels of resource consumption in the following way: $\tilde{\chi}: 0.1 \Rightarrow 0.3$. Figure 2 provides the simulation results. When $\tilde{\chi}$ is increased, it is faster for the habit stock of resource consumption to converge to the current consumption level. As identified in the plot, the change in the speed of adjustment has no effects on the equilibrium values of the variables in the system. Nevertheless, the transitional paths towards the equilibrium points of the variables are affected. We now examine the effects 
on the transitional paths of the variables. As $\tilde{\chi}$ is magnified, the habit stock of resource consumption is initially lessened. The lessened habit stock decreases the relative propensity to consume resource. Accordingly, the consumption level of resource is diminished. The resource stock is augmented as the consumption level of resource is lessened. The output level of the industrial sector is augmented and the output of the resource sector is lowered. The price of resource falls in association with a falling demand for resource. The net impact on the GDP (is the sum of the values of the output levels of the two sectors) is positive. The rate of interest becomes lower in association with a rising level of the total wealth (capital). The industrial sector attracts some labor force from the resource sector.

Figure 2

The Weights of More Distant Values of Resource Consumption Being Lowered
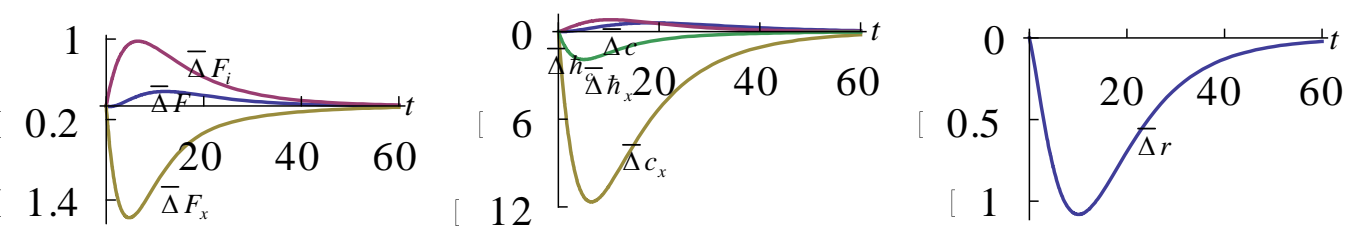

0.2
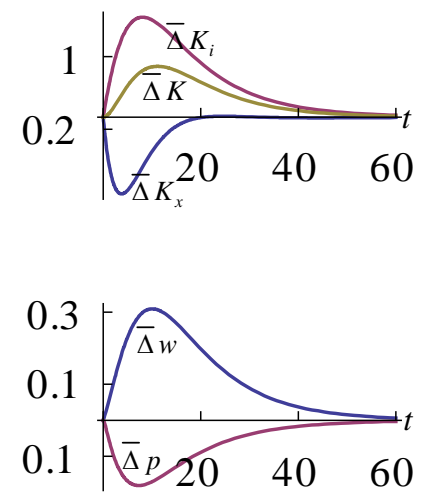
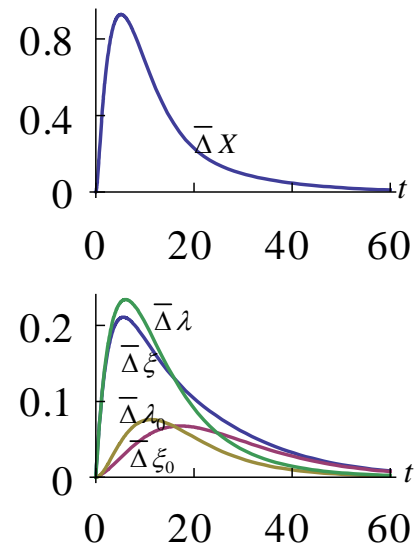
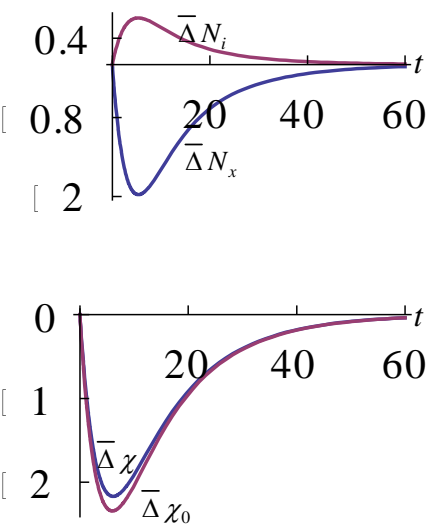

\section{Augmenting the resource carrying capacity}

We now let the carrying capacity of resource to be increased as follows: $\phi: 1 \Rightarrow 1.1$. Figure 3 plots the simulation results. As the resource carrying capacity is increased, the resource stock is increased. There are economic structural changes in the dynamic system. The price of resource is reduced in association with the argumentation in the resource stock.

The wage rate is slightly increased. The industrial sector abstracts some of the labor force from the resource sector. The capital input of the resource sector is also reduced. Both the output level of the resource sector and the consumption level of resource are diminished. In association with falling in the consumption, the habit stock of resource consumption falls. The falling in the habit stock lessens weakened the propensity to consume the resource.

As the industrial sector is enlarged, the wealth is increased. The increase in the wealth increases the propensity to save. The total capital is further increased till the system achieves the equilibrium point. The GDP falls as a net result of the rise in the industrial sector's output, and falls in the resource sector's output and the rice of the resource. 
Figure 3

An Increase in the Resource Carrying Capacity
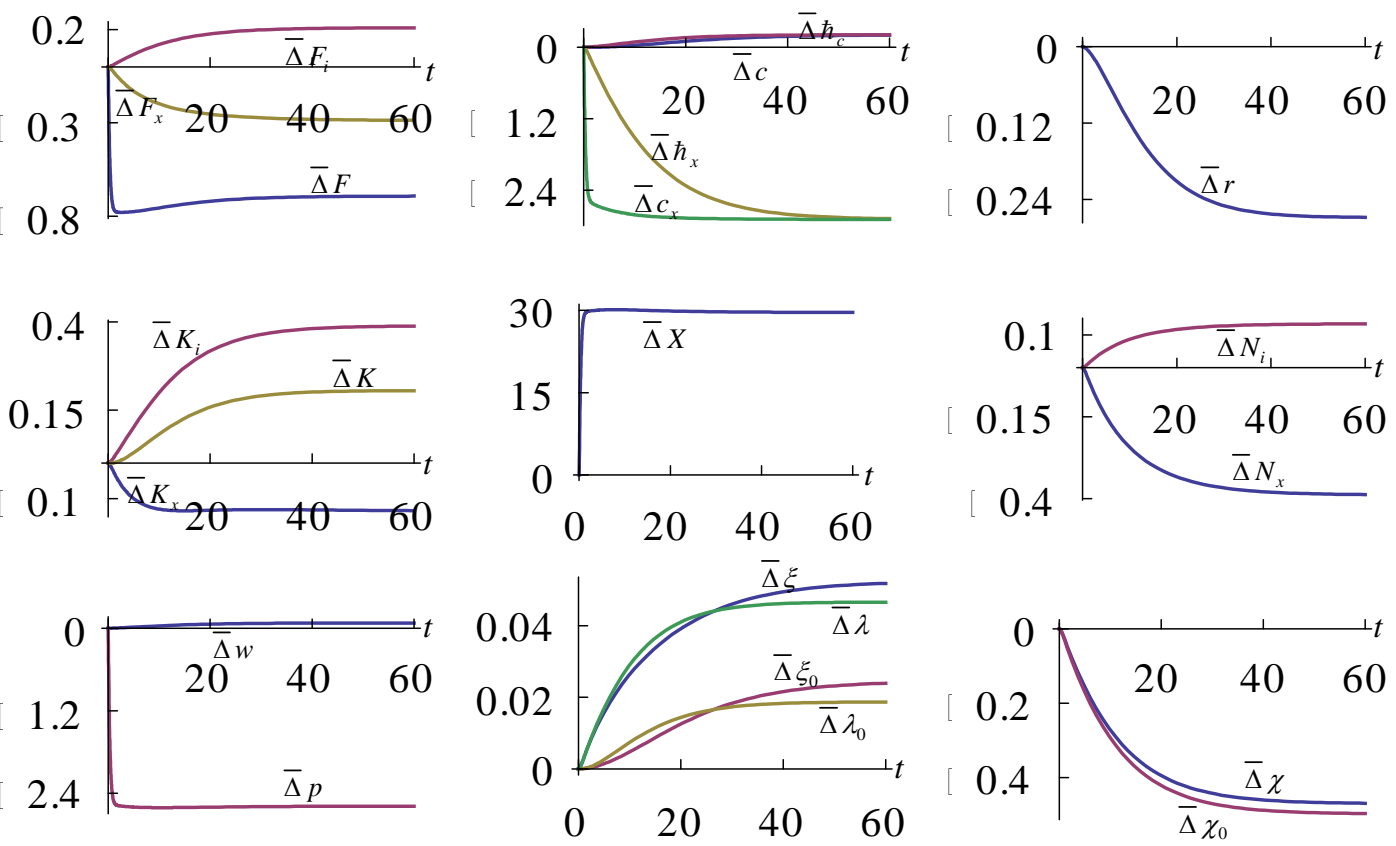

The habit stock of the resource affecting the propensity to consume resource more strongly

We now allow the habit stock of resource consumption to impress the propensity to consume the resource more strongly in the following way: $\chi_{h}: 0.02 \Rightarrow 0.04$. The impact of the change is to increase the propensity to consume the resource. This increase enhances both current level of resource and the habit stock of resource consumption. As the demand is increased, the price of the resource rises. The output of the resource sector is increased in association with rising demand. More labor force is employed by the resource sector.

Figure 4

Strengthening the Impact of Habit Stock ofResource Consumption
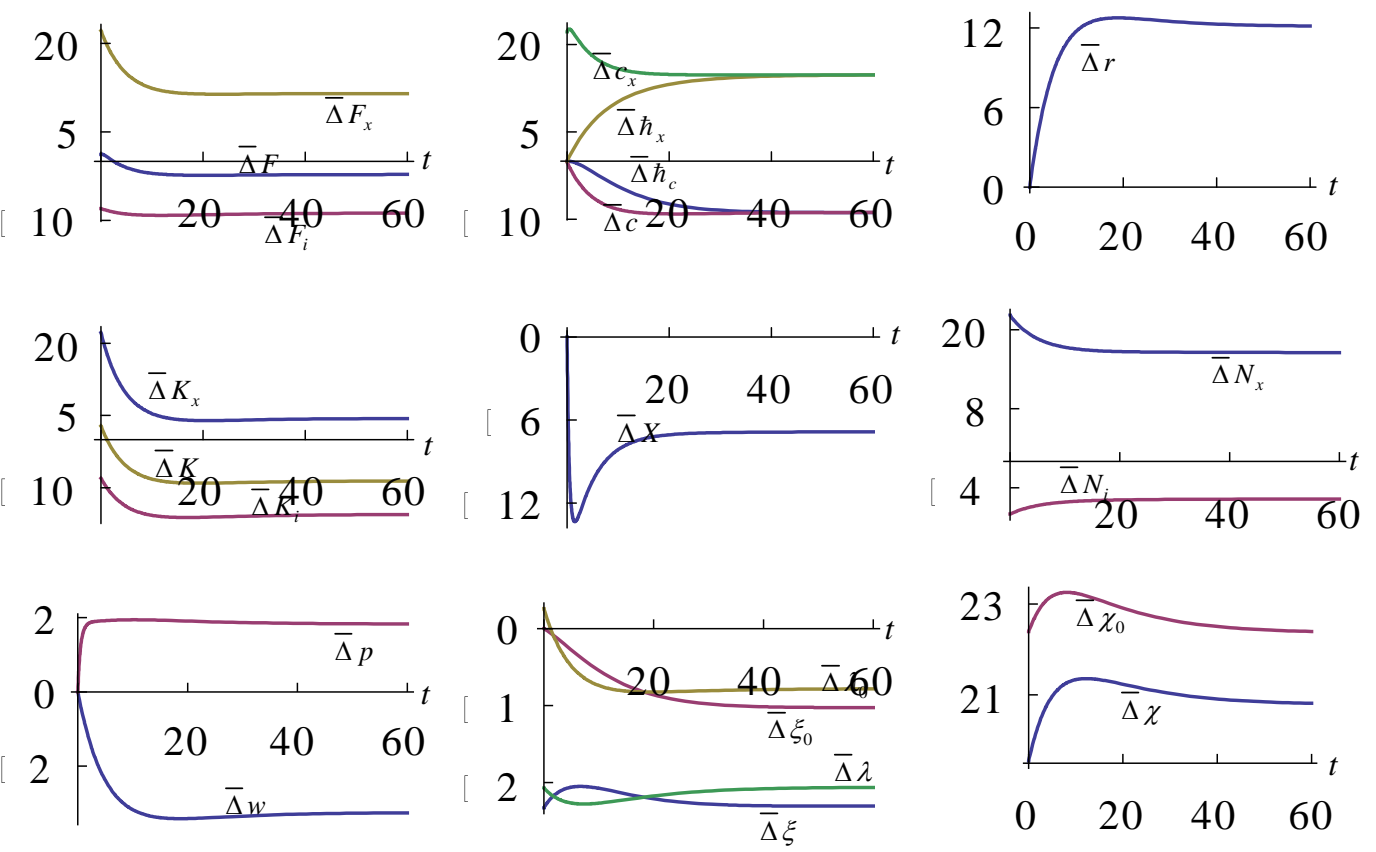
The resource sector also employs more capital inputs. The output of industrial sector and its two inputs are lessened as the propensities to consume the commodity and to save are reduce. The GDP rises initially but subsequently falls. The reduction in the total capital is associated with rising in the rate of interest. As the resource sector's output level is augmented, the stock of resource is lowered.

\section{The propensity to save being more strongly affected by wealth}

The impact of the propensity to save on economic growth, structure is a lasting challenging question in economics. Adam Smith and Keynes have different opinions about the effects of a change in the saving propensity. Nevertheless, few formal economic models explicitly deal with interactions between propensity to save and other aspects of economic systems. We now use our model to explain what happen to the economic system as the propensity to save is more strongly affected by wealth: $\lambda_{k}: 0.02 \Rightarrow 0.03$. The initial consequence of the change is to augment the propensity to save. In association with falling in the relative propensity to save, the relative propensities to consume the commodity and the resource are diminished. Initially the habit stocks of resource and resource consumption and the consumption levels are lessened, but subsequently these variables are increased. These changes are associated with the motion of the total capital. Initially the household saves more, less are available for consumption. As saving is continued, the economy has more capital. The increased capital enables the two sectors to employ more capital and increase product. The price of the resource and the rate of interest reduced, the wage rate is increased. The industrial sector attracts more labor force from the resource sector. As time passes, some of the labor force is attracted back to the resource sector. The output level of the resource sector lowers initially and subsequently rises. The GDP is augmented.

Figure 5

The Impact of Wealth on the Propensity to Save Being Strengthened
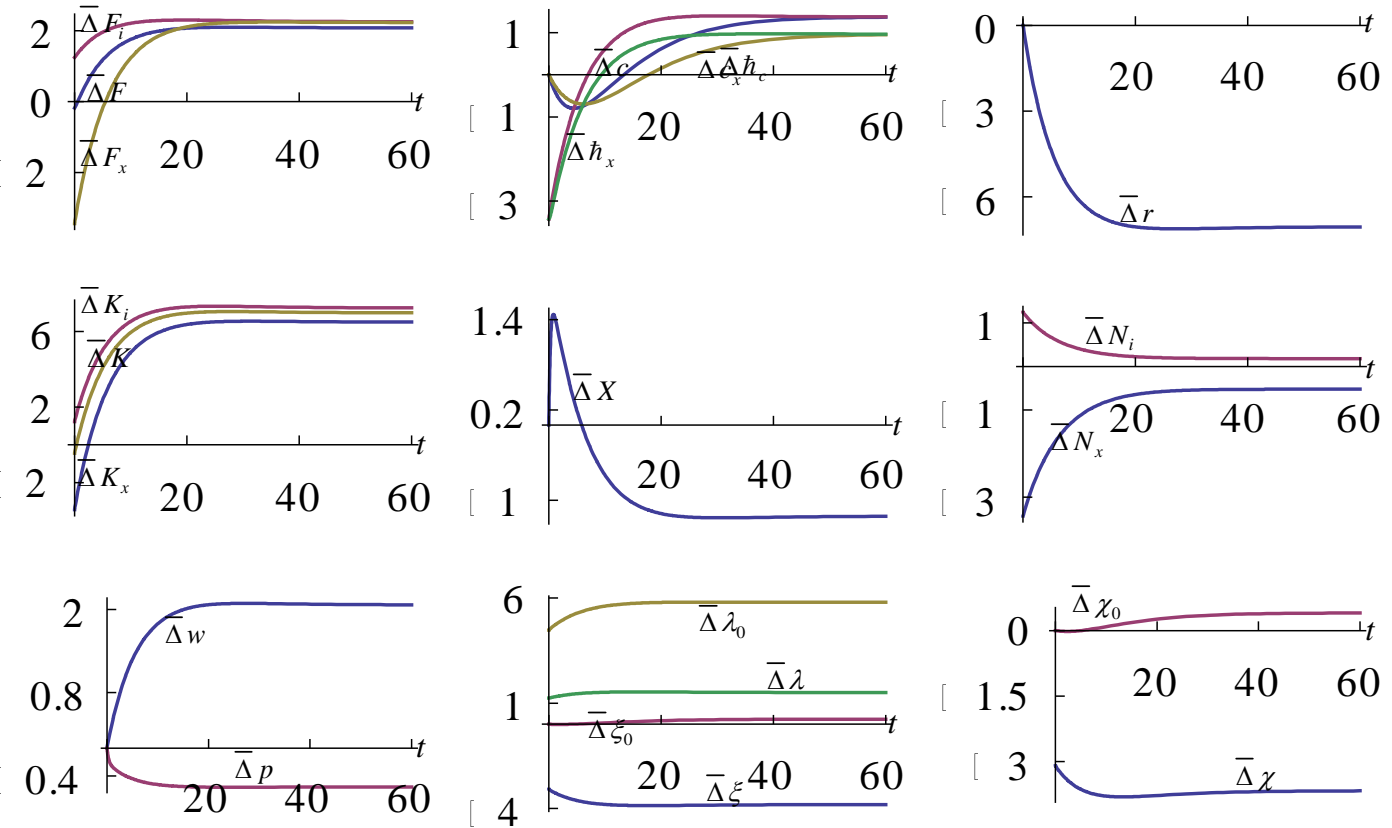

\section{Concluding Remarks}

This paper introduced habit formation and preference changes into a neoclassical growth model with renewable resources. The production side is according to the neoclassical growth theory with renewable resources. Although it is influenced by the Ramsey growth theory with time preference and habit formation, this paper applies a new approach the household behavior proposed by Zhang (1993).The study focuses on interactions among economic growth, 
resource utilization and growth, labor and capital distribution, habit formation and time preference in an integrated framework. Because we can simulate the motion of the whole economy with any given set of the parameters, we can deal with transitional processes as well as economic equilibrium. The economic system is given by the four-dimensional time-invariant system.

We simulated the motion of the economy. The comparative dynamic analyses were conducted with regard to a few parameters. The analyses provided some insights. For instance, as the weights of more distant values of the consumption level of the renewable resource are lowered, it is faster for the habit stock of resource consumption to converge to the current consumption level; the parameter change has no effects on the equilibrium values of the variables.

The transitional paths towards the equilibrium points of the variables are affected as follows: while the habit stock of resource consumption is initially lessened, the relative propensity to consume resource falls; the consumption level of resource is diminished and the resource stock is augmented; the industrial sector attracts more the labor force from the resource sector to; the output level of the industrial sector is augmented and the output of the resource sector is lowered; the price of resource and the rate of interest fall; the net impact on the GDP and the national wealth are positive.

Because of its comprehensive economic structure, we may refine our model and integrate other ideas in economics in different ways. It is reasonable, for instance, to take account of other forms of resource ownership. The government may intervene in economic production, resource harvesting, factor distribution, and income and wealth distribution in various forms. We may also include leisure time as an endogenous variable.

\section{References}

1. Abel, A., Bernanke, B.S., Croushore, D. (2007), Macroeconomics, Prentice Hall, New Jersey.

2. Alvarez-Cuadrado, F., Monteriro, G., Turnovsky, S.J. (2004), „Habit formation, catching-up with the joneses, and economic growth", Journal of Economic Growth, Vol. 9, No. 1, pp. 47-80.

3. Alvarez-Cuadrado, F., von Long, N. (2011), "Consumption and renewable resource extraction under alternative property-rights regimes", Resource and Energy Economics, Vol. 33, No.4, pp. 1028-53.

4. Amato J.D., Laubach, T. (2004), "Implication of habit formation for optimal monetary policy", Journal of Monetay Economics, Vol. 51, No.2, pp. 305-25.

5. Ayong Le Kama, A.D. (2001), "Sustainable growth, renewable resources and pollution", Journal of Economic Dynamics and Control, Vol. 25, No. 12, pp. 1911-18.

6. Barbier, E.B. (1999), „Endogenous growth and natural resource scarcity", Environmental and Resource Economics, Vol. 14, No.1, pp. 51-74.

7. Barro, R.J., Sala-i-Martin, X. (1995) Economic Growth, McGraw-Hill.

8. Becker, G. S. (1992), "Habits, addictions and traditions", Kyklos, Vol. 45, No. 3, pp. 327-45.

9. Becker, G.S., Mulligan, C.B. (1997), "The endogenous determination of time preference", The Quarterly Journal of Economics, Vol. 112, No. 3, pp. 729-58.

10. Beltratti, A., Chichilnisky, G., and Heal, G.M. (1994), „Sustainable Growth and the Golden Rule", in Goldin, I., Winters, I.A. (Eds.) The Economics of Sustainable Development, Cambridge University Press, Cambridge.

11. Blanchard, O.J., Fischer, S. (1989) Lectures on Macroeconomics, MIT Press.

12. Boldrin, M., Christiano, L., Fisher, J. (2001), „Habit persistence, asset returns, and the business cycle", American Economic Review, Vol. 91, No.1, pp. 149-66.

13. Brander, J.A. and Taylor, M.S. (1998), "The simple economics of easter island: A RicardoMalthus model of renewable resource use", American Economic Review, Vol. 81, No. 1, pp. 119-38.

14. Burmeister, E., Dobell, A.R. (1970), Mathematical Theories of Economic Growth, Collier Macmillan Publishers.

15. Cairns, D.R., Tian, H.L. (2010), "Sustained development of a society with a renewable resource", Journal of Economic Dynamics \& Control, Vol. 24, No. 6, pp. 2048-61.

16. Campbell, J., Cochrane, J. (1999), „By force of habit: A consumption-based explanation of 
aggregate stock market behavior", Journal of Political Economy, Vol. 107, No.2, pp. 205-51.

17. Carroll, C.D. (2000), "Solving consumption models with multiplicative habits", Economics Letters, Vol. 68, No.1, pp. 67-77.

18. Chang, W.Y., Tsai, H.F., Chang, J.J. (2011), „Endogenous time preference, interest-rate rules, and indeterminacy", The Japanese Economic Review, Vol. 62, No.2, pp. 348-64.

19. Chao, L.W., Szrek, H., Pereira, N.S., Paul, M. (2009), "Time preference and its relationship with age, health, and survival probability", Judgment and Decision Making, Vol. 4, No.1, pp. 1-19.

20. Chen, C.H., LU, Z.N. (2009), „Analysis of the economical growth model with limited renewable resource", International Journal of Nonlinear Science, Vol. 7, No. 1, pp. 90-4.

21. Clark, C.W. (1976), Mathematical Bioeconomics: The Optimal Management of Renewable Resources, Wiley.

22. Corrado, L., Holly, S. (2011), "Multiplicative habit formation and consumption: A note", Economics Letters, Vol. 113, No. 2, pp. 116-19.

23. Das, M. (2003), "Optimal growth with decreasing marginal impatience", Journal of Economic Dynamics and Control, Vol. 27, No. 10, pp. 1881-98.

24. Dasgupta, P.S., Heal, G.E. (1979), The Economics of Exhaustible Resources, Cambridge University Press.

25. De la Croix, D. (1996), "The dynamics of bequeathed tastes“, Economics Letters, Vol. 51, No.1, pp. 89-96.

26. Deaton, A., Muellbaver, J. (1980) Economics and Consumer Behavior, Cambridge University Press.

27. Dioikitopoulos, E.V., Kalyvitis, S. (2010), „Endogenous time preference and public policy: growth and fiscal implications", Macroeconomic Dynamics, Vol. 14, No. S2, pp. 243-57.

28. Dornbusch, R., Frenkel, J. (1973), "Inflation and growth: Alternative approaches", Journal of Money, Credit and Banking, Vol. 50, No. 1, pp. 141-56.

29. Drugeon, J.P. (1996), "Impatience and long-run growth", Journal of Economic Dynamics and Control, Vol. 20, No. 1-3, pp. 281-313.

30. Drugeon, J.P. (2000), "On the roles of impatience in homothetic growth paths", Economic Theory, Vol. 15, No. 1, pp. 139-61.

31. Duesenberry, J. (1949), Income, Saving, and the Theory of Consumer Behavior, Harvard University Press.

32. Eliasson, L., Turnovsky, S.J. (2004), „Renewable resources in an endogenously growing economy: Balanced growth and transitional dynamics", Journal of Environmental Economics and Management, Vol. 48, No. 3, pp. 1018-49.

33. Epstein, L.G. (1987), „A simple dynamic general equilibrium model", Journal of Economic Theory, Vol. 41, No. 1, pp. 68-95.

34. Fuchs, V.R. (1982), "Time PREFERENCE AND Health: An Exploratory Study", in Fuchs, V.R. (Ed.) Economic Aspects of Health, University of Chicago Press, Chicago.

35. Gómez M.A. (2008), „Convergence speed in the AK endogenous growth model with habit formation", Economics Letter, Vol. 100, No.1, pp. 16-21.

36. Gordon, H.S. (1954), "The economic theory of a common property resource: The fishery", Journal of Political Economy, Vol. 62, No. 2, pp. 124-42.

37. Gylfason, T., Herbertsson, T., Zoega, G. (1999), „A mixed blessing: Natural resources and economic growth", Macroeconomic Dynamics, Vol. 3, No. 2, pp. 204-25.

38. Hannesson, R. (2000), "Renewable resources and the gains from trade", Canadian Journal of Economics, Vol. 33, No. 1, pp. 122-32.

39. Hirose, K.I., Ikeda, S. (2008), "On decreasing marginal impatience", Japanese Economic Review, Vol. 59, No. 3, pp. 259-74.

40. Horioka, C. (1990), "Why is Japan's households saving so high? A literature survey", Journal of the Japanese and International Economics, Vol. 4, No. 1, pp. 49-92.

41. Huang, M.M. (2012), „Housing deep-habit model: Mutual implications of macroeconomics and asset pricing", Economics Letters, Vol. 116, No.6, pp. 526-30.

42. Jinji, N. (2006), „International trade and terrestrial open-access renewable resources in a small open economy", Canadian Journal of Economics, Vol. 39, No. 3, pp. 790-808.

43. Kam, E., Mohsin, M. (2006), "Monetary policy and endogenous time preference", Journal of Economic Studies, Vol. 33, No. 1, pp. 52-67.

44. Kirby, K.N., Godoy, R., Reyes-Garcia, V., Byron, B., Apaza, L., Leonard, W., Perez, B., Vadez, V., 
Wilkie, D. (2002), „Correlates of delay-discount rates: Evidence from Tsimane Amerindians of the Bolivia rain forest", Journal of Economic Psychology, Vol. 23, No. 3, pp. 291-316.

45. Lise, L., Seitz, S. (2011), "Consumption inequality and intra-household allocations", The Review of Economic Studies, Vol. 78, No. 1, pp. 328-55.

46. Lucas, R.E. Jr., Stokey, N.L. (1984), "Optimal growth with many consumers", Journal of Economic Theory, Vol. 32, No. 1, pp. 139-71.

47. Lusardi, A. (1996), „Permanent income, current income, and consumption: Evidence from two panel data set", Journal of Business \& Economic Statistics, Vol. 14, No. 1, pp. 81-90.

48. Mehra, R., Prescott, E. (1985), "The equity premium: A puzzle", Journal of Monetary Economics, Vol. 15, No.2, pp. 145-61.

49. Meng, Q. (2006), "Impatience and Equilibrium Indeterminacy", Journal of Economic Dynamics and Control, Vol. 30, No. 2, pp. 2671-92.

50. Miles, D., Scott, A. (2005), Macroeconomics - Understanding the Wealth of Nations, John Wiley \& Sons.

51. Obstfeld, M. (1990), "Intertemporal dependence, impatience, and dynamics", Journal of Monetary Economics, Vol. 26, No. 1, pp. 45-75.

52. Palivos, T., Wang, P., Zhang, J. (1997), "On the existence of balanced equilibrium", International Economic Review, Vol. 38, No. 1, pp. 205-24.

53. Persson, T., Svensson, L. (1985), "Current account dynamics and the terms of trade: Harberger-Laursen-Metzler two generations later", Journal of Political Economy, Vol. 93, No. 1, pp. 43-65.

54. Plourde, G.C. (1970), „A simple model of replenishable resource exploitation", American Economic Review, Vol. 60, No. 3, pp. 518-22.

55. Plourde, G.C. (1971), „Exploitation of common-property replenishable resources", Western Economic Journal, Vol. 9, No. 3, 256-66.

56. Ravn, M., Schmitt-Grohe, S., Uribe, M. (2006), "Deep habits", Review of Economic Studies, Vol. 73, No. 1, pp. 195-218.

57. Sachs, J.D., Warner, A.M. (2001), "The curse of natural resources", European Economic Review, Vol. 45, No. 4-6, pp. 827-38.

58. Schaefer, M.B. (1957), „Some considerations of population dynamics and economics in relation to the management of marine fisheries", Journal of Fisheries Research Board of Canada, Vol. 14, No. 5, 669-81.

59. Sheldon, G. (1998), Fashioning a Culture of Diligence and Thrift: Savings and Frugality Campaigns in Japan, 1990-1931, University of Hawaii Press.

60. Shi, S., Epstein, L.G. (1993), "Habits and time preference", International Economic Review, Vol. 34, No. 1, pp. 61-84.

61. Solow, R. (1956), "A Contribution to the Theory of Economic Growth", Quarterly Journal of Economics, Vol. 70, No. 1, pp. 65-94.

62. Solow, R. (1999), "Neoclassical Growth Theory“, in Taylor, J.B., Woodford, M. (Eds.), Handbook of Macroeconomics, North-Holland, Amsterdam.

63. Stern, M.L. (2006), "Endogenous time preference and optimal growth“, Economic Theory, Vol. 29, No. 1, pp. 49-70.

64. Stiglitz, J.E. (1967), "A two sector two class model of economic growth", Review of Economic Studies, Vol. 34, No. 2, pp. 227-38.

65. Storesletten, K., Telmer, C., Yaron, A. (2004), "Consumption and risk sharing over the life cycle", Journal of Monetary Economics, Vol. 51, No. 3, pp. 609-33.

66. Uzawa, H. (1968), „Time Preference, the Consumption Function, and Optimum Asset Holdings", in Wolfe, J.N. (Ed.), Valve, Capital and Growth: Papers in Honour of Sir John Hicks, Aldine, Chicago, pp. 485-504.

67. Zhang, W.B. (1993), „A woman's labor participation and economic growth: creativity, knowledge utilization and family preference", Economics Letters, Vol. 42, No. 1, pp. 105-10.

68. Zhang, W.B. (2011), „Renewable resources, capital accumulation, and economic growth", Business Systems Research, Vol. 2, No. 1, pp. 24-35.

69. Zhang, W.B. (2012), "Habits, saving propensity, and economic growth", Scientific Bulletin Economic Sciences, Vol. 11, No. 2, pp. 3-15. 


\section{Appendix: Proving Lemma 1}

We now solve the three autonomous differential equations and the procedure in the lemma. First, from (2) and (5), we get

$z \equiv \frac{\bar{\beta}_{i} K_{i}}{N_{i}}=\frac{\bar{\beta}_{x} K_{x}}{N_{x}}(\mathrm{~A} 1)$

where $\bar{\beta}_{j} \equiv \beta_{j} / \alpha_{j}, j=i, x$. Inserting (1) in (2), we have

$r(z)=\frac{\alpha_{i} A_{i} \bar{\beta}_{i}^{\beta_{i}}}{z^{\beta_{i}}}-\delta_{k}, w(z)=\frac{\beta_{i} A_{i} z^{\alpha_{i}}}{\bar{\beta}_{i}^{\alpha_{i}}}(\mathrm{~A} 2)$

where we use (A1). From (5), (4), and (A1), we solve

$p(z, X)=\frac{\bar{\beta}_{x}^{\alpha_{x}} w}{\beta_{x} A_{x} z^{\alpha_{x}} X^{b}}$. (A3)

From (6) and (A)), we get

$\bar{\beta}_{i} K_{i}+\bar{\beta}_{x} K_{x}=z N .(\mathrm{A} 4)$

From (12) and (14), we have $\chi \hat{y} N=p F_{x}$. Insert (7) and (5) in this equation

$(1+r) K+w N=\frac{\bar{\beta}_{x} K_{x} w}{z \beta_{x} \chi}(\mathrm{A} 5)$

where we also use (A1). From $K_{i}+K_{x}=K$, (A4) and (A5), we solve

$K_{x}(z, \chi)=\left[\frac{(1+r) z N}{\bar{\beta}_{i}}+w N\right]\left[\frac{\bar{\beta}_{x} w}{z \beta_{x} \chi}-1-r+\frac{(1+r) \bar{\beta}_{x}}{\bar{\beta}_{i}}\right]^{-1}$,

$K_{i}(z, \chi)=\frac{z N}{\bar{\beta}_{i}}-\frac{\bar{\beta}_{x} K_{x}}{\bar{\beta}_{i}}, K(z, \chi)=K_{i}+K_{x} \cdot(\mathrm{A} 6)$

From (14), we have

$\frac{\lambda_{0} N}{\lambda_{k}}=\left(\frac{\bar{\lambda}+\lambda_{w} w}{\lambda_{k}}\right) N+K$. (A7)

Insert (A6) in (A7)

$\lambda_{0}=\varphi_{0}+\varphi_{1}\left(\frac{\bar{\beta}_{x} w}{z \beta_{x} \chi}+\varphi_{2}\right)^{-1}(\mathrm{~A} 8)$

where

$\varphi_{0}(z)=\bar{\lambda}+\lambda_{w} w+\frac{\lambda_{k} z}{\bar{\beta}_{i}}, \varphi_{1}(z) \equiv \lambda_{k}\left(1-\frac{\bar{\beta}_{x}}{\bar{\beta}_{i}}\right)\left[\frac{(1+r) z}{\bar{\beta}_{i}}+w\right], \varphi_{2}(z) \equiv \frac{(1+r) \bar{\beta}_{x}}{\bar{\beta}_{i}}-1-r$.

Substituting $\chi=\chi_{0} /\left(\xi_{0}+\lambda_{0}+\chi_{0}\right)$ into (A8) yields 
$\lambda_{0}^{2}+\omega_{1} \lambda_{0}-\omega_{2}=0$ (A9)

where

$$
\begin{aligned}
& \omega_{0}\left(z, \xi_{0}\right) \equiv \frac{z \beta_{x} \chi_{0}}{\bar{\beta}_{x} w}, \omega_{1}\left(z, \xi_{0}, \chi_{0}\right) \equiv \omega_{0}\left[\frac{\bar{\beta}_{x} w\left(\xi_{0}+\chi_{0}\right)}{z \beta_{x} \chi_{0}}+\varphi_{2}-\frac{\bar{\beta}_{x} \varphi_{0} w}{z \beta_{x} \chi_{0}}\right], \\
& \omega_{2}\left(z, \xi_{0}, \chi_{0}\right) \equiv \omega_{0}\left[\varphi_{0} \varphi_{2}+\varphi_{1}+\frac{\bar{\beta}_{x} \varphi_{0} w\left(\xi_{0}+\chi_{0}\right)}{z \beta_{x} \chi_{0}}\right] .
\end{aligned}
$$

We solve (A9)

$$
\lambda_{0}\left(z, \xi_{0}, \chi_{0}\right)=\frac{-\omega_{1} \pm \sqrt{\omega_{1}^{2}+4 \omega_{2}}}{2} .
$$

Equation (A9) has two solutions. In our simulation case the solution

$$
\lambda_{0}\left(z, \xi_{0}, \chi_{0}\right)=\frac{-\omega_{1}+\sqrt{\omega_{1}^{2}+4 \omega_{2}}}{2} .
$$

is meaningful. From (16) and (18), we have

$\xi_{0}\left(z, \hbar_{c}\right)=\bar{\xi}+\xi_{w} w+\xi_{h} \hbar_{c}$,

$\chi_{0}\left(z, \hbar_{x}\right)=\bar{\chi}+\chi_{w} w+\chi_{x} \hbar_{x}$ (A 11$)$

By the following procedure we can determine all the variables as functions of $z, X, \hbar_{c}, \hbar_{x}: r$ and $w$ by $(\mathrm{A} 2) \rightarrow p$ by $(\mathrm{A} 3) \rightarrow \xi_{0}$ and $\chi_{0}$ by $(\mathrm{A} 11) \rightarrow \lambda_{0}$ by (A10) $\rightarrow \lambda, \xi$, and $\chi$ by (10) $\rightarrow K_{i}$ and $K_{x}$ by (A6) $\rightarrow K=K_{i}+K_{x} \rightarrow k=K / N \rightarrow N_{i}$ and $N_{x}$ by (A1) $\rightarrow F_{i}$ by (1) $\rightarrow F_{x}$ by (4) $\rightarrow \hat{y}$ by (7) $\rightarrow c, c_{x}$ and $s$ by (10). Here, we express the function for wealth obtained by this procedure as $k=\phi\left(z, X, \hbar_{c}, \hbar_{x}\right)$. From (11), (3), (15) and (17) and the procedure to determine the variables as functions of $z, X, \hbar_{c}, \hbar_{x}$, we have

$$
\begin{aligned}
& \dot{k}=\bar{\Lambda}\left(z, X, \hbar_{c}, \hbar_{x}\right) \equiv \lambda \hat{y}-k, \quad(\mathrm{~A} 12) \\
& \dot{X}=\Lambda_{X}\left(z, X, \hbar_{c}, \hbar_{x}\right) \equiv \phi_{0} X\left(1-\frac{X}{\phi}\right)-F_{x}, \\
& \dot{\hbar}_{c}=\Lambda_{c}\left(z, X, \hbar_{c}, \hbar_{x}\right) \equiv \tilde{\xi}\left(c-\hbar_{c}\right),(\mathrm{A} 13) \\
& \dot{\hbar}_{x}=\Lambda_{x}\left(z, X, \hbar_{c}, \hbar_{x}\right) \equiv \tilde{\chi}\left(c_{x}-\hbar_{x}\right) .
\end{aligned}
$$

Taking derivatives of $k=\phi\left(z, X, \hbar_{c}, \hbar_{x}\right)$ with respect to time yields

$$
\dot{k}=\frac{\partial \phi}{\partial z} \dot{z}+\Lambda_{X} \frac{\partial \phi}{\partial X}+\Lambda_{c} \frac{\partial \phi}{\partial \hbar_{c}}+\Lambda_{x} \frac{\partial \phi}{\partial \hbar_{x}}(\mathrm{Al} 14)
$$

where we use (A13). We do not provide the expressions as they are tedious. Solve (A12) and (A14)

$$
\dot{z}=\Lambda_{z}\left(z, X, \hbar_{c}, \hbar_{x}\right) \equiv\left(\bar{\Lambda}-\Lambda_{X} \frac{\partial \phi}{\partial \hbar_{X}}-\Lambda_{c} \frac{\partial \phi}{\partial \hbar_{c}}-\Lambda_{x} \frac{\partial \phi}{\partial \hbar_{x}}\right)\left(\frac{\partial \phi}{\partial z}\right)^{-1} .
$$

We thus proved Lemma 1. 


\section{About the author}

Wei-Bin Zhang, PhD (Umeå, Sweden), is Associate Dean of Graduate School of Management, Professor (since 2000 till now) in Ritsumeikan Asia Pacific University (APU), Japan. He graduated in 1982 from Department of Geography, Beijing University, China, and completed graduate study at Department of Civil Engineering, Kyoto University, Japan. After he completed his dissertation on economic growth theory under supervision of Prof. Ake $E$ Andersson with Prof. Michio Morishima as the main examiner, he researched at the Swedish Institute for Futures Studies in Stockholm for 10 years. He also worked as visiting scholars in USA, Japan, Mainland China, Austria, Singapore and Hong Kong. His main research fields are nonlinear economic dynamics, growth theory, trade theory, East Asian economic development, and Confucianism. He has published about 200 academic articles 95 in peerreview international journals), authorized 22 academic books in English by international publishing houses. Prof. Zhang is editorial board members of 7 peer-review international journals. Author can be contacted at wbz1@apu.ac.jp 